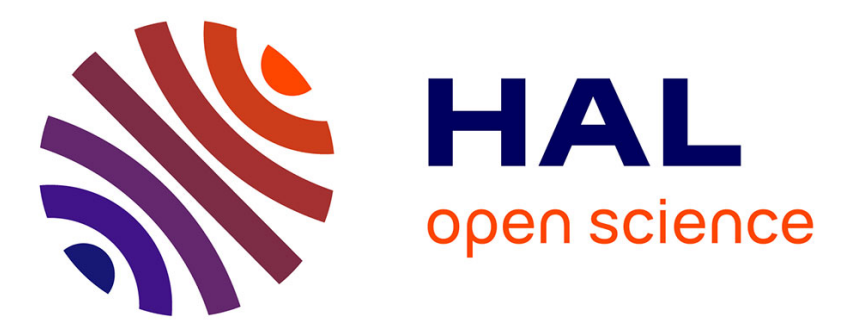

\title{
Lateral development influenced by position on the shoot-reassessment on apple shoots bent during active growth and in the following winter
}

Hyun Hee Han, Pierre-Eric Lauri, Charlotte Coutand

\section{To cite this version:}

Hyun Hee Han, Pierre-Eric Lauri, Charlotte Coutand. Lateral development influenced by position on the shoot-reassessment on apple shoots bent during active growth and in the following winter. 27. International Horticultural Congress, Aug 2006, Seoul, South Korea. pp.435-439. hal-01000438

\section{HAL Id: hal-01000438 \\ https://hal.science/hal-01000438}

Submitted on 3 Jun 2020

HAL is a multi-disciplinary open access archive for the deposit and dissemination of scientific research documents, whether they are published or not. The documents may come from teaching and research institutions in France or abroad, or from public or private research centers.
L'archive ouverte pluridisciplinaire HAL, est destinée au dépôt et à la diffusion de documents scientifiques de niveau recherche, publiés ou non, émanant des établissements d'enseignement et de recherche français ou étrangers, des laboratoires publics ou privés. 


\title{
Lateral Development Influenced by Position on the Shoot-Reassessment on Apple Shoots Bent during Active Growth and in the Following Winter
}

\author{
H.H. Han and P.E. Lauri \\ INRA - UMR BEPC \\ 2 Place Pierre Viala \\ 34060 Montpellier Cedex 1 \\ France
}

\author{
C. Coutand \\ INRA - UMR PIAF \\ 234 Avenue du Brezet \\ 63100 Clermont-Ferrand \\ France
}

Keywords: apple, bending, flowering, branching, organogenesis

\begin{abstract}
The effects of bending on shoot growth and lateral development depend on several factors such as the phenological stage, the duration of bending and the angle of re-orientation. An arching experiment was carried out on five apple cultivars to analyze the effects of the phenological stage at which bending was carried out and the position on the shoot on lateral development. Arching was done in the proximal zone of shoots during spring, when shoots were one third of their final lengths and in the distal zone of shoots after bud organogenesis was completed in the following winter. In all cases, arching was carried out to put shoots under the same mechanical strain. Analyses were done on the arched portion of shoots, with a comparison of the frequencies of laterals in the upper and lower faces of shoots. In both bending treatments, there was a significant increase in the proportion of aborted buds on the lower face, with an increase of sylleptic branches in shoots bent in spring and an increase of inflorescences in shoots bent in winter on the upper face. In shoots bent in winter, inflorescences on the upper face had larger leaves than inflorescences in the lower face. Our results suggested that the effect of branch re-orientation on lateral development may act on both bud organogenesis when bending is carried out during active growth (spring), and bud post-organogenesis when the same manipulation is done during winter before bud break. The interest of branch re-orientation to control branching (intensity and lateral fate) is discussed as an alternative to avoid chemicals.
\end{abstract}

\section{INTRODUCTION}

Shoot bending is known to decrease terminal shoot growth and to alter lateral development, i.e., proportion and possibly final length of the various lateral types (latent, vegetative, inflorescence). Several factors have been shown to influence lateral development, especially genotype, angle of the shoot, and the phenological period during which the manipulation is performed (Lakhoua and Crabbé, 1975). However, in most studies, the level of arching is quantitatively poorly controlled. So that if the "same" arching (e.g., same mass added) is imposed to shoots that exhibit differences in geometrical characteristics (length, diameter), then the shoots are subjected to very different mechanical state. Thus, if differences of sensitivity to arching are found, they can only be due to a different imposed mechanical state (due to genetic variability in shoot geometry) and not to a genetic variability of sensitivity to arching. Biomechanical studies of the effect of mechanical state on shoot growth and branching have demonstrated i) the importance of taking into account shoot geometry for a proper control of the imposed mechanical state, and ii) that plants perceive the level of strain and not of force (Coutand and Moulia, 2000).

This paper is part of a project studying the effects of bending on apple shoot architecture, biomechanics and hydraulics. In our work, we segregate through appropriate bending the genetic variability of sensitivity of cultivars to mechanical state due to arching from the genetic variability due to shoot geometrical differences if arching is uncontrolled. An original biomechanical protocol of arching was designed: the genetic variability of shoot geometry was taken into account and the level of imposed curvature was adapted for each cultivar in order to ensure that all the shoots were subjected to the 
same mechanical state of strain (i.e., slender shoots were more arched than stouter ones). The objective of the present study was to assess five cultivars for the effects on lateral development of position around the arched part of shoots for shoots bent at two phenological stages, i.e., during active growth (active organogenesis of the axillary production) and in the following winter (after organogenesis was done).

\section{MATERIALS AND METHODS}

Five cultivars presenting contrasted shoot shape (e.g., slenderness) and architecture (branching density, frequency of vegetative shoots and inflorescences on 1-year-old wood) were chosen: 'Ariane', 'Braeburn', 'Fuji', 'Gala', and 'Granny Smith'. One-year-old trees, grafted on Pajam rootstock, were planted in a completely randomized design in two adjacent rows in February 2004, in the INRA experimental field in Montpellier, France. Trees were pruned at planting to leave 3 to 5 buds at the bottom of the scion. The most vigorous 2004-shoot was then selected for the experiment after bud-break.

Arching was carried out by tying down the distal part of shoots in early June 2004 (Spring Bending, SB) and in mid-January 2005 (Winter bending, WB). In SB, the arched zone generally included the whole-shoot, whereas in WB it included the distal half of the shoot. At the time of bending, the length of shoots varied from 37 to $54 \mathrm{~cm}$ for SB, and from 125 to $150 \mathrm{~cm}$ for $\mathrm{WB}$, depending on the cultivar.

For each treatment, approximately 20 trees of 'Fuji' and 'Braeburn', and 10 trees of 'Ariane', 'Gala' and 'Granny Smith' were planted in a completely randomized design (each tree represented a replication).

In spring 2005, the arched zone of shoots was first determined on SB, including all nodes from the grafting point upwards to the uppermost node, and the same number of node downwards. The same number of nodes was then determined on the arched zone of WB shoots (Fig. 1). Each lateral was characterized by its type and position around the shoot. In the former case, five types were considered: sylleptic (i.e., branch which developed in the same year as bending was carried out, S), latent bud (L), vegetative bud (V), inflorescence (I), and aborted bud (i.e., which began to grow in spring 2005 and soon died, AB). In the latter case, the position around the shoot was designated by dividing the cross-section circumference of the shoot into four quarters. Only the upper quarter and the lower quarter, hereafter referred to as upper (U) and lower (L) face, respectively, were evaluated (Fig. 1). The percentage of each lateral type was then computed considering all laterals on $\mathrm{U}$ and $\mathrm{L}$ faces.

For data analysis, we compared the percentages of each lateral type between the $U$ and $\mathrm{L}$ faces for the two bending treatments and for each cultivar. For inflorescences of WB shoots, the number of leaves more than $2 \mathrm{~cm}$ long was determined (sample size was too small in SB shoots). The Kruskal-Wallis non-parametric test was used to compare percentages, and the Newman-Keuls test was used to compare number of leaves of inflorescences (STATISTICA statistical package, StatSoft, France).

\section{RESULTS}

An ANOVA revealed that the proportion of lateral types differed significantly among cultivars (data not shown). As explained in the Introduction, as the genetic variability of shoot diameter (which can lead to a variability of mechanical state of the arched branch if the same curvature is imposed) has been compensated by different guide radii in arching treatments, these first results suggested a genetic variability of the sensitivity to strain between cultivars. Further statistical analysis is now required to see if the studied cultivars can be clustered by their level of sensitivity.

Within each cultivar, the comparison of bud types in the upper and lower faces of the arched shoot showed the following results:

(1) In SB shoots, most of the differences between $U$ and $L$ faces were detected for $S$ and $A B$ types. For the five cultivars, there was a higher percentage of $S$ in the $U$ face compared to the $\mathrm{L}$ face, and inversely, a higher percentage of $\mathrm{AB}$ in the $\mathrm{L}$ face, compared to the $U$ face, with significant differences in all cases (Fig. 2). 
(2) In WB shoots, most of the differences between U and L faces were detected for I and $A B$ types. For the five cultivars, there was a higher percentage of $I$ in the $U$ face compared to the $\mathrm{L}$ face, and inversely, a higher percentage of $\mathrm{AB}$ in the $\mathrm{L}$ face, compared to the $U$ face (Fig. 3). Differences were significant in all cases except for $\mathrm{AB}$ in Gala $(P=0.059)$ and in Braeburn $(P=0.157)$.

(3) Eventually, the number of inflorescence leaves more than $2 \mathrm{~cm}$ significantly increased in the $\mathrm{U}$ face, compared to the $\mathrm{L}$ face for the five cultivars (Fig. 4).

\section{DISCUSSION}

Bending significantly altered lateral development. Our results suggested two different mechanisms of lateral growth regulation, depending on the time of bending. Spring bending likely activated a mechanism which stimulated sylleptic branching on the upper face of the arched shoots to the detriment of bud organogenesis in the lower face. Winter bending activated a post-organogenesis mechanism with the abortion of already formed buds. We are conducting more fundamental research on bending by studying changes in water balance and hydraulics, as suggested by Kim et al. (2004), and with biomechanical analysis of sensitivity to arching among cultivars and relationships between level of applied strain and types of buds. We are also developing applied research to further experiment with timing and duration of bending during the growing season and the effects on vegetative growth and flowering of various cultivars.

In the context of sustainable integrated and organic horticulture, bending may be used as an alternative means to manage branching without chemicals. In spur-bound cultivars, it may be efficient to reduce spur density which is known to have deleterious effects on fruit quality and crop regularity.

\section{Literature Cited}

Coutand, C. and Moulia, B. 2000. Biomechanical study of the effect of a controlled bending on tomato stem elongation: local strain sensing and spatial integration of the signal. J. of Exper. Bot. 51:1825-1842.

Kim, S.H., Shackel, K.A. and Lieth, J.H. 2004. Bending alters water balance and reduces photosynthesis of rose shoots. J. of the Amer. Soc. Hort. Sci. 129:896-901.

Lakhoua, H. and Crabbé, J. 1975. Arcure et gravimorphisme chez le Pommier. I. Effets de divers degrés d'arcure sur la forme de la ramification et l'expression de la vigueur. Bulletin Rech. Agron. Gembloux 10:43-54. 
The upper face (U) Uppermost bud

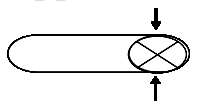

The lower face (L)

Circular metallic guide of known radius

( $\mathrm{R}$ guide)

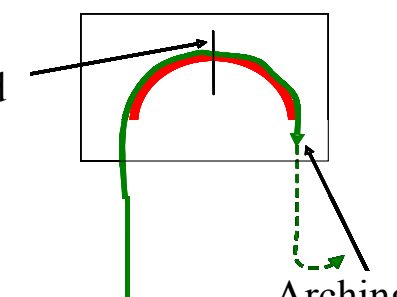

Arching done by placing the tip of the shoot in
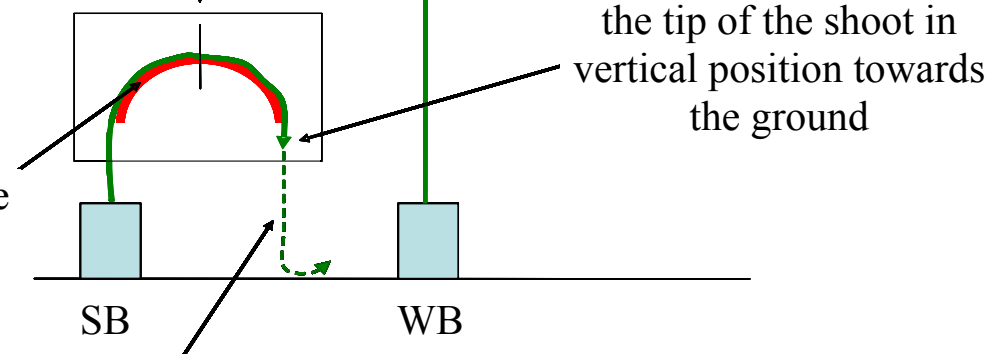

Growth of the shoot after arching

Fig. 1. Quantitative control of arching and determination of the arched zone in shoots bent in spring (SB) and in winter (WB). Arching was started in the apical part of the shoot in order to place the apical bud in a vertical position towards the ground. The arched zone corresponds to the portion of the shoot rolled on the guide; the uppermost bud is located at the middle of the arched zone.

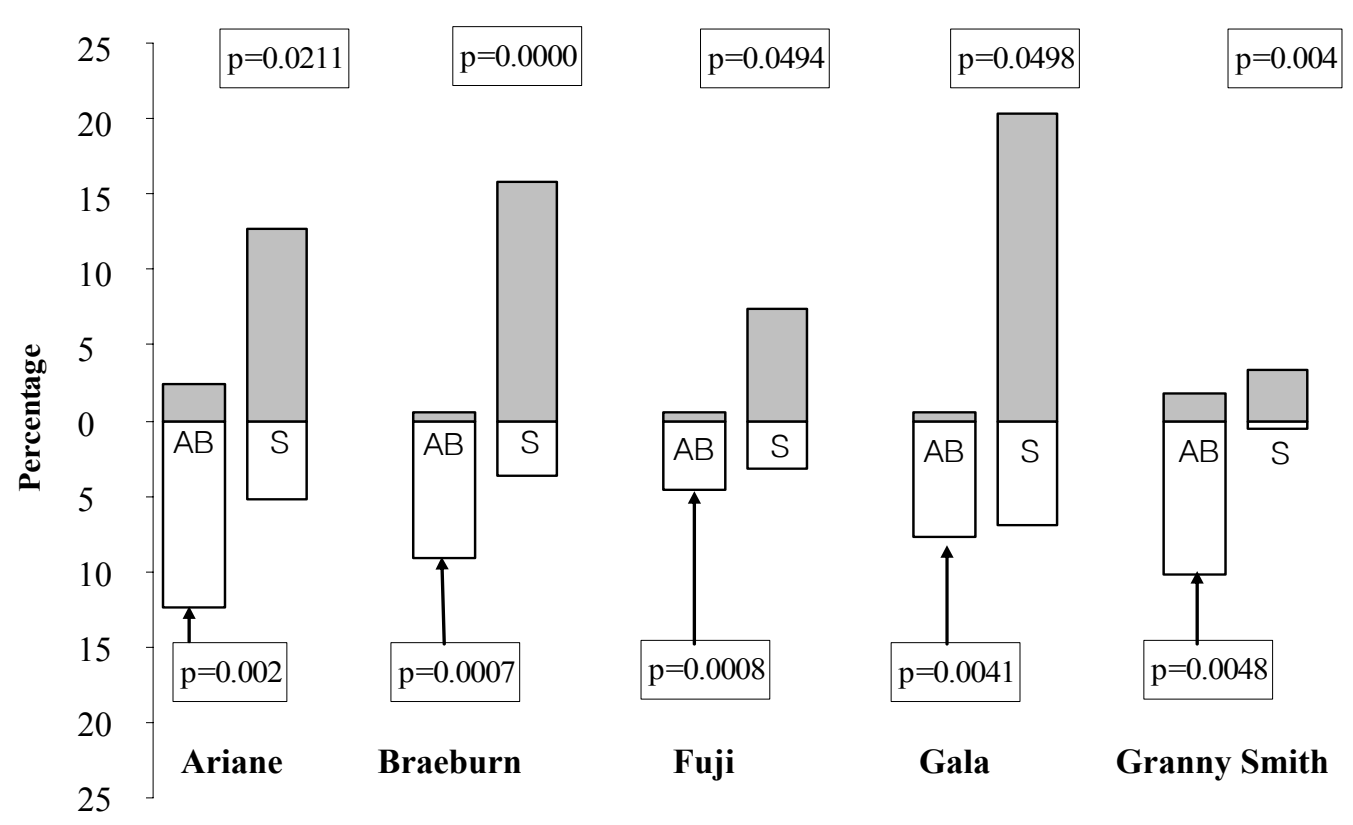

Fig. 2. Percentage of aborted buds (AB), and sylleptic shoots $(\mathrm{S})$ on shoots bent in spring (SB) according to position of the lateral in upper (U) and lower (L) faces of the shoot for the five cultivars. For each cultivar, the Kruskal-Wallis test compared percentages of $\mathrm{AB}$ and $\mathrm{S}$ on $\mathrm{U}$ and $\mathrm{L}$ faces. 


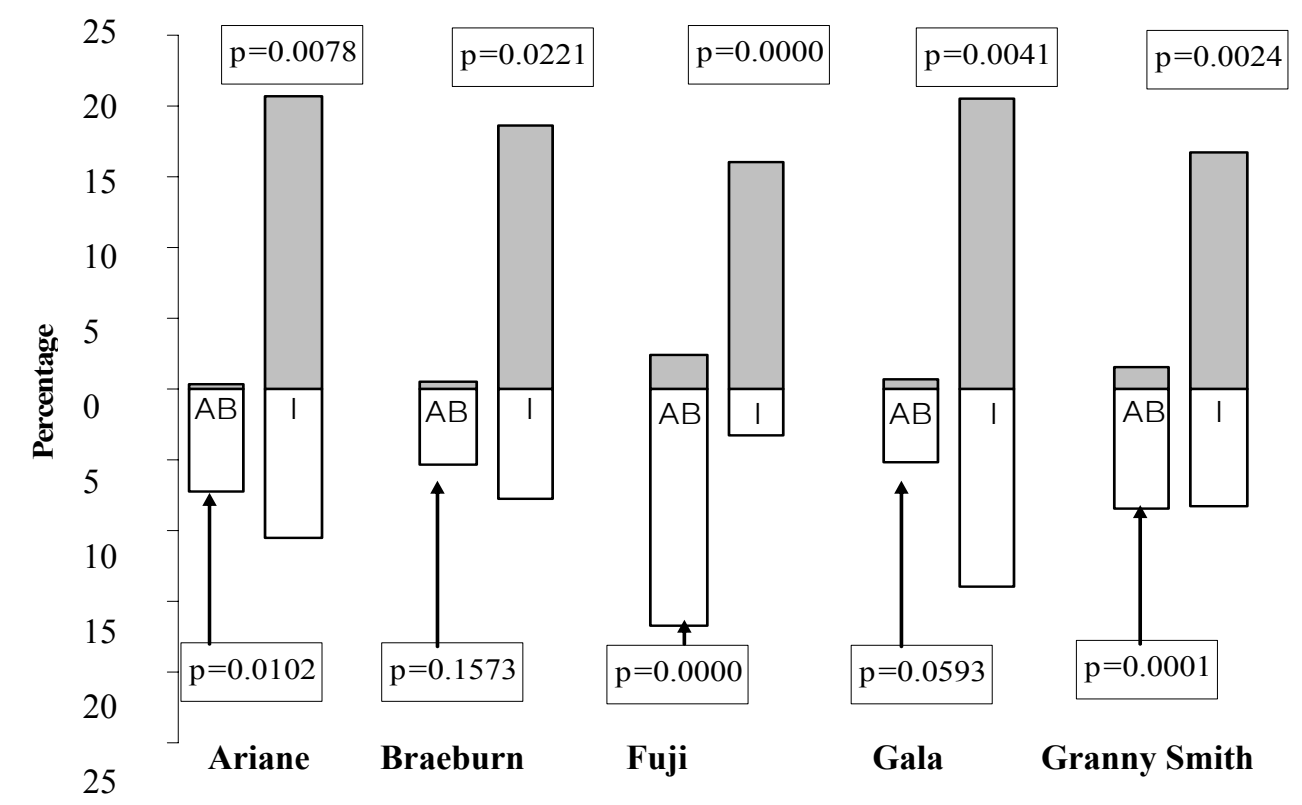

Fig. 3. Percentage of aborted buds (AB), and inflorescence (I) on shoot bent in winter (WB), according to position of the lateral in upper (U) and lower (L) faces of the shoot for the five cultivars. For each cultivar, the Kruskal-Wallis test compared percentages of $\mathrm{AB}$ and $\mathrm{I}$ on $\mathrm{U}$ and $\mathrm{L}$ faces.

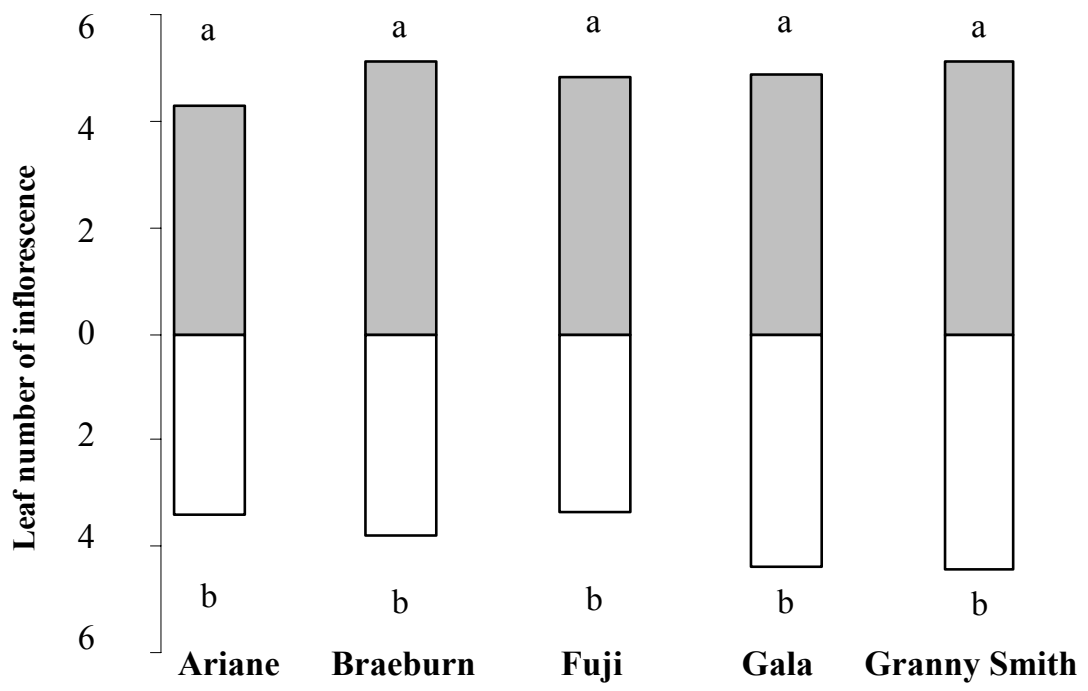

Fig. 4. Number of leaves of the inflorescence on shoot bent in winter (WB), according to position of the lateral in upper (U) and lower (L) faces of the shoot for the five cultivars. For each cultivar, the Newman-Keuls test compared leaf number on $U$ and $\mathrm{L}$ faces. 
